\title{
Yes, trust, but not unconditional
}

\author{
Minh-Hoang Nguyen \\ ISR, Phenikaa University
}

Yen Nghia, Ha Dong district, Hanoi 100803, Vietnam

In a newly published article in Journal of Experimental Social Psychology, O’Brien, Palmer \& Albarracin [1] postulated that:

First, participants who trust science are more likely to believe and disseminate false claims that contain scientific references than false claims that do not. Second, reminding participants of the value of critical evaluation reduces belief in false claims, whereas reminders of the value of trusting science do not.

The direct implication of these findings leads the authors to conclude that "conclude that trust in science, although desirable in many ways, makes people vulnerable to pseudoscience."

From another angle, we can see that trust in science should not be given, which is exactly why science needs tools to strengthen the trust of academia and the public. In this regard, I believe that reforming retraction notices can be one practical and effective way [2]. Retractions tell us all that science is not scientism and can become fallible at times. But its self-correcting mechanism basically functions well.

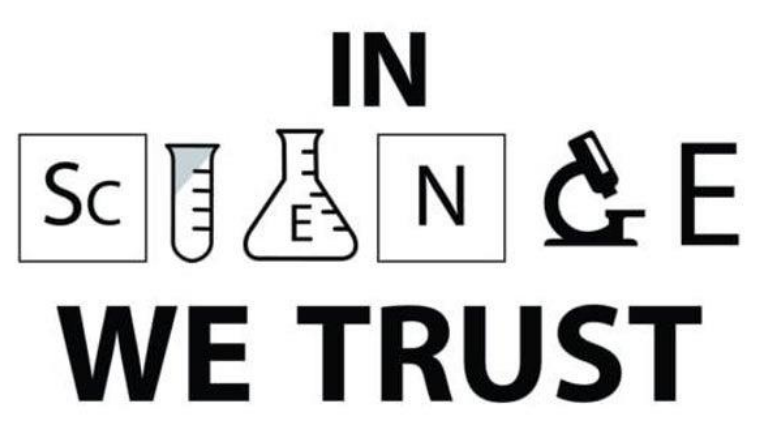


In addition, the specific recommendation of [2] that journals should require authors to self-report the paper's limitations and weaknesses makes science "more complete". The paradox is that when these tools present science as vulnerable to mistakes, they help to reinforce the trust in earnest science, but not the funky, self-congratulating and colorful pseudoscience.

Therefore, yes, trust is required for science to become useful. But the trust is not unconditional. And here open science has a role to play [3].

\section{References}

[1] O’Brien, T. C., Palmer, R., \& Albarracin, D. (2021). Misplaced trust: When trust in science fosters belief in pseudoscience and the benefits of critical evaluation. Journal of Experimental Social Psychology, 96, 104184.

[2] Vuong, Q. H. (2020). Reform retractions to make them more transparent. Nature, 582(7811), 149.

[3] Vuong, Q. H. (2017). Open data, open review and open dialogue in making social sciences plausible. Nature: Scientific Data Updates (December 12). Retrieved from: https://go.nature.com/2QdnUrW 